\title{
Children who are overweight or obese: Attitudes and beliefs of nursing students in Taiwan
}

\author{
Tuan-I Tsai*1,2, Lauretta Luck $^{1}$, Diana Jefferies ${ }^{1}$, Lesley Wilkes ${ }^{1,3}$ \\ ${ }^{1}$ School of Nursing and Midwifery, Western Sydney University, Australia \\ ${ }^{2}$ Department of Nursing, Chung Hwa University of Medical Technology, Taiwan \\ ${ }^{3}$ Centre for Nursing and Midwifery Research, Nepean Hospital, Australia
}

Received: October 20, 2018

DOI: $10.5430 /$ cns.v7n1p89
Accepted: November 13, $2018 \quad$ Online Published: November 26, 2018

URL: https://doi.org/10.5430/cns.v7n1p89

\begin{abstract}
Background: Overweight/obesity has increased worldwide in recent decades. The prevalence of children who are overweight/obese has also increased in Taiwan. Nursing professionals' attitudes and beliefs may affect the quality of care for children who are overweight and obese.

Purpose: To explore the attitudes and beliefs of nursing students about children who are overweight/obese in Taiwan.

Methods: A self-administered translated questionnaire was completed by two groups (2-year program and 4-year program) of undergraduate nursing students in Taiwan. Data were analysed using descriptive statistics and $t$-test.

Results: Data from this study indicated that two groups (2-year program and 4-year program) of undergraduate nursing students hold positive attitudes towards overweight/obese children. The 2-year program nursing students held more neutral attitudes about overweight/obese children. Neither group had strong beliefs related to children's eating habits.

Conclusions: Education is one way to improve attitudes and beliefs towards childhood overweight/obesity. The data from this study provides information for the development of curricula for nursing students.
\end{abstract}

Key Words: Paediatric obesity, Overweight, Student, Nursing, Attitude, Taiwan

\section{INTRODUCTION}

Overweight/obesity has increased in both developing and developed countries in recent decades. The prevalence of children who are overweight/obese has also increased in Taiwan. Between 1991 and 2003, the percentage of male overweight and obese students increased from $5.7 \%$ to $14.2 \%$ and from $7.9 \%$ to $17.4 \%$, respectively. The prevalence of female overweight and obese students increased from $11.1 \%$ to $13.4 \%$ and from $3.1 \%$ to $4.1 \%$, respectively. Covariance analysis indicates that both genders in 2003 had significantly higher percentages of overweight/obese children than those in 1991 and 1997. ${ }^{[1]}$ The 2015 Taiwan Ministry of Education
"Student Health Survey", found the prevalence rates of childhood overweight/obesity was $28.7 \%$ in elementary school students (32.4\% amongst boys and $24.7 \%$ amongst girls), and $29.2 \%$ in junior high students $(33.3 \%$ among boys and $24.8 \%$ among girls). ${ }^{[2]}$

The rise in childhood overweight/obesity increases the chances of a child becoming overweight/obese adults and they may suffer both physical and psychological health problems. The physical problems include type 2 diabetes, ${ }^{[3]}$ fatty liver disease and obstructive sleep apnoea. ${ }^{[4]}$ Overweight/obese children could face higher risks for psychological problems, such as low self-esteem, depression and body

*Correspondence: Tuan-I Tsai; Email: T.Tsai@westernsydney.edu.au; Address: School of Nursing and Midwifery, Western Sydney University, Locked Bag 1797, Penrith South DC, NSW, 2751, Australia. 
dissatisfaction. ${ }^{[5]}$

There are numerous factors that contribute to childhood overweight/obesity. Evidence in the literature points to the children's behavioural patterns such as dietary habits, a lack of physical activity, and sedentary behaviour (watching TV and using computers $)^{[6,7]}$ makes them prone to be overweight/obese in childhood.

Health professionals are an important point of contact and can provide advice about managing weight. However, researchers have found that health professionals had negative attitudes toward adult overweight/obese patients. ${ }^{[8,9]}$ In the study by Foster et al. in $2003^{[8]}$ over $50 \%$ of physicians described obese patients as awkward, unattractive, ugly, and non-compliant. The findings were similar within a group of nurses. Gujral, Tea, and Sheridan in 2011 ${ }^{[10]}$ revealed that nurses might have negative perceptions about obese patients. Ward-Smith and Peterson in 2016 ${ }^{[5]}$ found that nurse practitioners hold some negative attitudes and beliefs about overweight/obese people, such as overweight/obese individuals are not as good as other people, not as successful as others, are untidy, and not as healthy. After an extensive literature review, Snethen, Treisman, Buseh, and Kelber ${ }^{[11]}$ was the only study that explored the attitudes of nursing students towards childhood overweight/obesity. ${ }^{[12]}$ The results revealed that undergraduate nursing students appeared to have negative perceptions about children who are overweight/obese. ${ }^{[11]}$ Negative attitudes toward overweight/obese persons may affect the quality of care provided by health care professionals. A qualitative study by Shea and Gagnon ${ }^{[13]}$ reported that nurses experienced discomfort and exhaustion when providing care to overweight/obese patients. Education might be one method to reduce negative attitudes and the impact this has on the relationships between health care providers and patients.

Research indicates that various education interventions can improve health professional's attitudes ${ }^{[10,14]}$ and beliefs ${ }^{[15]}$ about overweight/obese people. An educational module using written material for health professionals has shown some success in decreasing negative attitudes. ${ }^{[14]}$ However, not every education method is effective. Marcum in 2009 ${ }^{[15]}$ revealed that viewing an education session altered nurses' and nursing students' beliefs about obese people, but the attitudes toward obese people did not change. Providing education about overweight/obesity can support nurses to provide professional health care to these patients. ${ }^{[16]}$

The aim of the study was to explore the attitudes, beliefs and knowledge of nursing students about children who are overweight/obese in Taiwan. This paper reports the findings of the student nurses' attitudes and beliefs. Attitudes and beliefs are complex concepts that are not easily defined. An individual's attitude has a strong impact on his or her behaviour. ${ }^{[17]}$ For the purpose of this study, attitude is defined as a cognitive affective assessment that is shaped by experience and influences behaviour and evaluations of objects, events or conditions. ${ }^{[18]}$ In simple terms, it is an expression of whether someone feels that "something is good or bad" and this influences behaviours. Belief is defined as "an acceptance that something exists or is true". [19]

\section{MeTHODS}

\subsection{Research design}

A descriptive quantitative design was utilised in this study. Descriptive quantitative designs are developed to gain information about characteristics within people, a situation, or group, and are usually conducted when little is known about a phenomenon. ${ }^{[20]}$

\subsection{Tool}

In this study, the survey consisted of two sections: attitudes and beliefs; and demographics.

The survey tool was adapted from Allison's scale on Attitudes Toward Obese Persons Scale (ATOP) and Beliefs About Obese Persons Scale (BAOP). ${ }^{[21]}$ Following a pilot study in Taiwan with 115 nursing students, psychometric testing of the tool was undertaken and the final scale consisted of 19 items and revealed three factors. The first two, selfconcept and social relationships, measured attitudes. The third factor, poor eating behaviour, measured beliefs. ${ }^{[22]}$ In presenting the results of section 1 , these factors will be used. The section on demographics sought the participants' characteristics related to their age, gender, weight and height.

The survey was translated from English into the local language (Mandarin) by a trained translator and back-translated into English to ensure the mandarin characters truly represent the English words in the original tool. ${ }^{[23,24]}$ Analysis on the process of translation is published in a professional journal. ${ }^{[25]}$ The survey was provided in Mandarin to ensure the nursing students in Taiwan understood the questions.

\subsection{Sample and setting}

This study was undertaken at a university in South Taiwan and final year nursing students were invited to participate. Data were collected on March, 2017 using the translated survey. Participants were recruited on a voluntary basis during the students' weekly meeting times.

In Taiwan, there are several educational programs available for students to obtain a Bachelor of Nursing degree. In this study, data were collected from two separate groups of students, from either a 2-year program or 4-year Bachelor of 
Nursing program, as explain below. The 2-year Program is a two-phase nursing program. Students enter a five-year junior college program to obtain an Associate Bachelor degree in nursing. These students have completed junior high school and commence their studies in junior college when they are approximately 15 years old. At the end of the fiveyear program, these students are required to pass a national examination to register as a registered nurse. The graduates of the five-year program can continue their education by completing a 2-year Bachelor of Nursing program. In the 4-year Program, students enrol in a 4-year Bachelor of Nursing degree program after completing senior high school at approximately 18 years old. After the students receive their degree when they are approximately 22 years, they are also required to pass the national examination before registering as a Registered Nurse.

\subsection{Data analysis}

Data were entered directly into and analysed with SPSS ${ }^{\circledR}$ version 22 software. ${ }^{[26]}$ All items in the first section were scored 1 to 5 . The scores on items related to attitude marked with an ${ }^{*}$ in the tables, where a score of 5 would indicate a negative attitude, were reversed. This is because the question was written in the negative. The mean score greater than three means a more positive attitude; less than three means a more negative attitude. The items in the belief subscale were not reversed, the higher score reflected stronger beliefs. Each item scores were tallied and totals on all items calculated. Descriptive and psychometric statistics were used to analysis the data. Descriptive data analysis included frequencies, percentages, means, and standard deviations. Demographic characteristics were examined. Comparison of the attitude and beliefs scores within and between the students in 2-year and 4-year program were analysed using a $t$-test. The mean scores on the individual items are reported. Pearson's correlation coefficients was used to examine the relationship attitudes between beliefs and respondent's demographics. The level of significance was set at $p \leq .05$.

\subsection{Ethics}

Ethics approval (H11770) for this study was sought from the Human Research Ethics Committee (HREC) of Western Sydney University and the permission to access classes in the Bachelor of Nursing programs to collect data was obtain from the relevant university in Taiwan. The Plain Language Statement (PLS) provided full disclosure of the study and its aims, time involved, the risks and benefits, and how the researcher would protect the participant's privacy. The PLS and the consent form was originally written in English and then translated to Mandarin before being distributed to the students. The participants were informed that if they volunteered to complete the survey and return it to the researcher, Published by Sciedu Press consent was implied. All participants had the choice to volunteer or refuse to take part in project.

\section{RESULTS}

\subsection{Demographics}

One hundred and two student nurses in the 2-year program and one hundred and six students in the 4-year program participated the study. Almost all $(96.1 \%, \mathrm{n}=98)$ respondents were female in the 2-year program and $84.9 \%(n=90)$ were female in the 4-year program. The students in the 2-year program ranged in age from 21-29 $(88.2 \%, \mathrm{n}=90), 30-39$ $(7.8 \%, \mathrm{n}=8)$, and 40-49 $(2.9 \%, \mathrm{n}=3)$. The students in the 4-year program group ranged in age from 21-29 (97.2\%, $\mathrm{n}=103$ ). The authors calculated the BMI from the weight and height provided by the participants. Of the students in the 2-year program, $6.9 \%(\mathrm{n}=7)$ of the sample were "obese" (BMI greater than $\left.30 \mathrm{~kg} / \mathrm{m}^{2}\right)$ and $12.7 \%(\mathrm{n}=13)$ "overweight" (BMI 25-30 kg/m²), 70.6\% $(\mathrm{n}=72)$ were "normal" weight (BMI 18.5-25 kg/m²), and 9.8\% ( $\mathrm{n}=10)$ classified as "underweight" $\left(\mathrm{BMI}<18.5 \mathrm{~kg} / \mathrm{m}^{2}\right)$. Of the students in the 4-year program, $6.6 \%(n=7)$ of the sample were "obese" and $14.2 \%(n=15)$ "overweight", 59.4\% ( $=63)$ were "normal" weight, and $17.9 \%(\mathrm{n}=19)$ classified as "underweight" (see Table 1).

\subsection{Attitude}

\subsubsection{Attitude of nursing student of overweight/obese chil- dren: Self-concept}

In the self-concept category (see Table 2), the possible total scores ranged from 6 to 30 with an overall mean for 2-year program students $(\bar{x}=19.79)$ and 4-year program students $(\bar{x}=20.15)$ indicating that attitudes towards selfconcept of overweight/obese children were positive. The highest mean score was item 4, with the students in 2-year program $(\bar{x}=4.40, S D=0.735)$ having a stronger positive attitude that overweight/obese children can be as successful as other workers. Participants from the 4-year program had a similar positive attitude $(\bar{x}=4.41, S D=0.766)$. The negative attitudes were item 2 and 3 . Participants from the 2-year program $(\bar{x}=2.84, S D=0.941)$ perceived that most overweight/obese children are not as good as other children, and participants from 4-year program had a similar attitude $(\bar{x}=2.90, S D=0.894)$. In item 3 , both groups had similar negative attitudes when answering the question about whether overweight/obese children were more self-conscious than other children. The results from participants from the 2-year program were $(\bar{x}=2.75, S D=0.930)$ and the results from participants in the 4-year program were $(\bar{x}=2.83, S D=0.899)$. However, participants felt that overweight/obese children are happy, and as self-confident as non-overweight/obese children. 
Table 1. Characteristics of the sample

\begin{tabular}{lll}
\hline Characteristics & $\begin{array}{l}\text { 2-year program } \\
\boldsymbol{n}(\boldsymbol{\%})\end{array}$ & $\begin{array}{l}\text { 4-year program } \\
\boldsymbol{n}(\boldsymbol{\%})\end{array}$ \\
\hline Gender & $4(3.9)$ & $16(15.1)$ \\
- Male & $98(96.1)$ & $90(84.9)$ \\
- Female & 0 & 0 \\
- Missing data & $24.25,4.661$ & $22.62,0.971$ \\
Age $($ years; $\boldsymbol{M}, \mathbf{S D})$ & $90(88.2)$ & $103(97.2)$ \\
- $21-29$ & $8(7.8)$ & 0 \\
- $30-39$ & $3(2.9)$ & 0 \\
- $40-49$ & 1 & 3 \\
- Missing data & & $7(6.6)$ \\
BMI & $7(6.9)$ & $15(14.2)$ \\
- Obese $\left(\mathrm{BMI}>30 \mathrm{~kg} / \mathrm{m}^{2}\right)$ & $13(12.7)$ & $63(59.4)$ \\
- Overweight $\left(\mathrm{BMI} 25-30 \mathrm{~kg} / \mathrm{m}^{2}\right)$ & $72(70.6)$ & $19(17.9)$ \\
- Normal $\left(\mathrm{BMI} 18.5-25 \mathrm{~kg} / \mathrm{m}^{2}\right)$ & $10(9.8)$ & 2 \\
- Underweight $\left(\mathrm{BMI}<18.5 \mathrm{~kg} / \mathrm{m}^{2}\right)$ & 0 & \\
- Missing data & &
\end{tabular}

Table 2. Comparison of 2-year program and 4-year program students' attitude (self-concept) about childhood overweight/obesity

\begin{tabular}{|c|c|c|}
\hline $\begin{array}{l}\text { Attitude Factor 1: Self-concept } \\
\text { Item }\end{array}$ & Mean & Std. Deviation \\
\hline \multicolumn{3}{|c|}{ 1. Overweight/obese children are as happy as non-overweight/obese children. } \\
\hline - 2-year Program & 3.13 & 0.972 \\
\hline - 4-year Program & 3.23 & 0.983 \\
\hline \multicolumn{3}{|c|}{ 2. Most overweight/obese children feel that they are not as good as other children. } \\
\hline - 2-year Program & 2.84 & 0.941 \\
\hline - 4-year Program & 2.90 & 0.894 \\
\hline \multicolumn{3}{|c|}{ 3. Most overweight/obese children are more self-conscious than other children. } \\
\hline - 2-year Program & 2.75 & 0.930 \\
\hline - 4-year Program & 2.83 & 0.899 \\
\hline \multicolumn{3}{|c|}{ 4. Overweight/obese children cannot be as successful as other workers. } \\
\hline - 2-year Program & 4.40 & 0.735 \\
\hline - 4-year Program & 4.41 & 0.766 \\
\hline \multicolumn{3}{|c|}{ 6. Overweight/obese children are just as self-confident as other children. } \\
\hline - 2-year Program & 3.13 & 0.886 \\
\hline - 4-year Program & 3.15 & 0.944 \\
\hline \multicolumn{3}{|c|}{ 7. Most children feel uncomfortable when they associate with overweight/obese children. } \\
\hline - 2-year Program & 3.55 & 1.030 \\
\hline - 4-year Program & 3.67 & 0.913 \\
\hline \multicolumn{3}{|l|}{ Total } \\
\hline - 2-year Program & 19.79 & \\
\hline - 4-year Program & 20.15 & \\
\hline
\end{tabular}

Note. ${ }^{\text {data reversed }}$ 
There were no statistically significant differences in scores between 2-year and 4-year program in the self-concept category.

\subsubsection{Attitude of nursing student to overweight/obese chil- dren: Social relationships}

In the social relationships category (see Table 3), the possible total scores ranged from 7 to 35 with an overall mean for 2-year program students $(\bar{x}=26.91)$ and 4-year program students $(\bar{x}=27.92)$ indicating that attitudes towards the social relationship of overweight/obese children were positive. The highest mean score items were 5 and 11 . In item 5, participants from the 2-year program $(\bar{x}=4.17$, $S D=0.822)$ and 4-year program $(\bar{x}=4.20, S D=0.723)$ perceived that overweight/obese children are usually as tidy as other children.

Table 3. Comparison of 2-year program and 4-year program students' attitude (social relationships) about childhood overweight/obesity

\begin{tabular}{|c|c|c|}
\hline $\begin{array}{l}\text { Attitude Factor 2: Social relationships } \\
\text { Item }\end{array}$ & Mean & Std. Deviation \\
\hline \multicolumn{3}{|c|}{ 5. Severely overweight/obese children are usually untidy. ${ }^{*}$} \\
\hline - 2-year Program & 4.17 & 0.822 \\
\hline - 4-year Program & 4.20 & 0.723 \\
\hline \multicolumn{3}{|c|}{$\begin{array}{l}\text { 8. Most overweight/obese children have different personalities than non-overweight/obese } \\
\text { children." }\end{array}$} \\
\hline - 2-year Program & 3.19 & 1.022 \\
\hline - 4-year Program & 3.52 & 1.048 \\
\hline \multicolumn{3}{|c|}{ 9. Most overweight/obese children resent normal weight children. ${ }^{*}$} \\
\hline - 2-year Program & 3.70 & 0.793 \\
\hline - 4-year Program & 3.80 & 0.765 \\
\hline \multicolumn{3}{|c|}{ 10. Overweight/obese children are more emotional than non-overweight/obese children." } \\
\hline - 2-year Program & 3.62 & 0.912 \\
\hline - 4-year Program & 3.74 & 0.843 \\
\hline \multicolumn{3}{|c|}{ 11. Overweight/obese children should not expect to lead normal lives.* } \\
\hline - 2-year Program & 4.53 & 0.713 \\
\hline - 4-year Program & 4.61 & 0.612 \\
\hline \multicolumn{3}{|c|}{ 12. Overweight/obese children tend to have family problems. ${ }^{*}$} \\
\hline - 2-year Program & 3.94 & 1.088 \\
\hline - 4-year Program & 4.08 & 0.947 \\
\hline \multicolumn{3}{|c|}{$\begin{array}{l}\text { 13. One of the worst things that could happen to a person would be for him/her to become } \\
\text { overweight/obese." }\end{array}$} \\
\hline - 2-year Program & 3.77 & 1.004 \\
\hline - 4-year Program & 4.08 & 0.996 \\
\hline \multicolumn{3}{|l|}{ Total } \\
\hline - 2-year Program & 26.91 & \\
\hline - 4-year Program & 27.92 & \\
\hline
\end{tabular}

Note. *data reversed

With an overall mean of $4.53(S D=0.713)$ for the 2-year program students and $4.61(S D=0.612)$ for the 4-year program students on item 11 , most students felt that overweight/obese children should expect to lead normal lives. The lowest mean score was item 8. Participants from both the 2-year program $(\bar{x}=3.19, S D=1.022)$ and 4-year program $(\bar{x}=3.52, S D=1.048)$ had a negative attitude believing that overweight/obese children have different personalities than non-overweight/obese children. When children who are overweight/obese were compared to children who were not overweight/obese, the majority of the participants perceived that overweight/obese children are not more emotional and do not tend to have more family problems than non-overweight/obese children. 
Table 4. Comparison of 2-year program and 4-year program students' belief about childhood overweight/obesity

\begin{tabular}{|c|c|c|}
\hline $\begin{array}{l}\text { Belief Factor: Poor eating behaviour } \\
\text { Item }\end{array}$ & Mean & Std. Deviation \\
\hline \multicolumn{3}{|c|}{$\begin{array}{l}\text { 14. Overweight/obesity often occurs when eating is used as a form of compensation for lack } \\
\text { of love or attention. }\end{array}$} \\
\hline - 2-year Program & 3.06 & 0.973 \\
\hline - 4-year Program & 2.95 & 1.081 \\
\hline \multicolumn{3}{|c|}{ 15. Overweight/obesity is usually caused by overeating. } \\
\hline - 2-year Program & 2.68 & 1.073 \\
\hline - 4-year Program & 2.65 & 1.096 \\
\hline \multicolumn{3}{|c|}{ 16. Most overweight/obese children cause their problem by not getting enough exercise. } \\
\hline - 2-year Program & 3.50 & 0.920 \\
\hline - 4-year Program & 3.30 & 0.948 \\
\hline \multicolumn{3}{|c|}{ 17. Most overweight/obese children eat more than non-overweight/obese children. } \\
\hline - 2-year Program & 3.06 & 1.042 \\
\hline - 4-year Program & 2.95 & 0.909 \\
\hline \multicolumn{3}{|c|}{$\begin{array}{l}\text { 18. The majority of overweight/obese children have poor eating habits that lead to their } \\
\text { overweight/obesity. }\end{array}$} \\
\hline - 2-year Program & 3.67 & 0.894 \\
\hline - 4-year Program & 3.37 & 0.887 \\
\hline \multicolumn{3}{|c|}{$\begin{array}{l}\text { 19. Children can be addicted to food, just as others are addicted to drugs, and these children } \\
\text { usually become overweight/obese. }\end{array}$} \\
\hline - 2-year Program & 3.44 & 0.929 \\
\hline - 4-year Program & 3.14 & 0.910 \\
\hline \multicolumn{3}{|l|}{ Total } \\
\hline - 2-year Program & 19.40 & \\
\hline - 4-year Program & 18.37 & \\
\hline
\end{tabular}

An independent sample $t$-test was conducted to compare scores of each item between groups in the social relationships category. The result revealed a significant difference on the following items: item 8 , most overweight/obese children have different personalities than non-overweight/obese children $(t=-2.346, p=.020)$; item 13 , one of the worst things that could happen to a person would be for him/her to become overweight/obese $(t=-2.238, p=.026)$.

Although the result showed that both groups of students have positive attitudes about overweight/obese children, a comparison of the attitudes of 2-year program nursing students and 4-year program nursing students revealed that the 2-year program nursing students held a more neutral attitude about overweight/obese children.

\subsection{Belief of nursing student about overweight/obese children: Poor eating behaviour}

In the poor eating behaviour category (see Table 4 ), the possible total scores ranged from 6 to 30 with an overall mean for the 2-year program students $(\bar{x}=19.40)$ and the 4-year program students $(\bar{x}=18.37)$ indicating that neither cohort had strong beliefs related to children's eating habits and most items indicted a tendency to neutral beliefs. However, item 18 had an overall mean of $3.67(S D=0.894)$ for the 2-year program students and $3.37(S D=0.887)$ for the 4year program students, indicating that most students believed overweight/obese children have poor eating habits that lead to their overweight/obesity.

An independent samples $t$-test was conducted to compare scores of each item between groups in poor eating behaviour. The result revealed the significant difference on the following items: item 18, overweight/obese children have poor eating habits that lead to their overweight/obesity. ( $t=2.419$, $p=.016)$ and item 19, children can be addicted to food, just as others are addicted to drugs, and these children usually become overweight/obese ( $t=2.351, p=.020)$.

The relationship between attitude and gender, belief and gender, attitude and age, belief and age, attitude and BMI, belief and BMI was investigated using Pearson product-moment correlation coefficient. Among the 2-year program and 4- 
year program students, BMI category was not associated with differences in any of the attitudes or belief items. There was a small, positive correlation between poor eating behaviour and age in 2-year program, $r=0.202, \mathrm{n}=101, \mathrm{Sig}=0.042$. From this result, 2-year program students had stronger beliefs than 4-year program students. This indicates student in the 2-year program believed that poor eating behaviour is linked to overweight/obese children.

When scores for self-concept, social relationships and poor eating behaviour were totalled, there were no significant differences between groups (see Table 5).

Table 5. 2-year program and 4-year program students' total attitude and belief about childhood overweight/obesity

\begin{tabular}{|c|c|c|c|c|c|c|c|}
\hline Factors & $\mathbf{N}$ & Mean & Std. Deviation & Std. Error Mean & $t$ & $p$ & Range \\
\hline \multicolumn{8}{|l|}{ Self-concept } \\
\hline - 2-year program & 102 & 19.79 & 3.602 & 0.357 & \multirow{2}{*}{0.752} & \multirow{2}{*}{.453} & $10-29$ \\
\hline - 4-year program & 106 & 20.15 & 3.236 & 0.314 & & & $13-28$ \\
\hline \multicolumn{8}{|l|}{ Social relationship } \\
\hline - 2-year program & 102 & 26.91 & 4.025 & 0.399 & \multirow{2}{*}{1.888} & \multirow{2}{*}{.060} & $15-35$ \\
\hline - 4-year program & 106 & 27.92 & 3.710 & 0.360 & & & $15-35$ \\
\hline \multicolumn{8}{|c|}{ Poor eating behaviour } \\
\hline - 2-year program & 102 & 19.40 & 4.091 & 0.405 & \multirow{2}{*}{1.826} & \multirow{2}{*}{.069} & $9-29$ \\
\hline - 4-year program & 106 & 18.37 & 4.074 & 0.396 & & & $7-27$ \\
\hline
\end{tabular}

\section{DISCUSSION}

Previous research specifically focusing on nursing students' attitude towards overweight/obese children is limited. This is the first study about this topic in Taiwan, and a major finding from this study indicated that undergraduate nursing students hold positive attitudes towards overweight/obese children. A comparison of the attitudes of two groups of nursing students (2-year program and 4-year program) revealed that 2-year program nursing students held a more neutral attitude about overweight/obese children. There were also a difference between the groups in two items in the social relationships category. Neither group had strong beliefs related to children's eating habits. There was no association between the BMI of the participant and attitude or belief towards overweight/obese children.

This study found that nursing students' attitudes towards self-concept of overweight/obese children generally were positive. Nursing students perceived that overweight/obesity does not affected children's' future success. However, participants slightly agreed that overweight/obese children feel more self-conscious about their weight and felt they were not as good as others. This result is supported by a study conducted by Snethen et al. ${ }^{[11]}$ The study revealed that undergraduate nursing students did not perceive that overweight children felt as good about themselves as their normal-weight peers $(77 \%)$ and felt more self-conscious (88\%). In Chinese culture, fatness is a sign of wealth, fertility and good health. Parents frequently express their love to their children by serving food, which may cause the child's obesity problems. ${ }^{[27]}$

Published by Sciedu Press
Therefore it may be that these nursing students see overweight/obesity as normal. The study also demonstrated that the self-concept of Chinese children are less impacted by obesity than Western children. ${ }^{[28]}$ It showed that in Chinese cultural, overweight/obesity can be more accept than in Western culture. A qualitative study by Chen et al. ${ }^{[29]}$ revealed that most of overweight/obese Taiwanese adolescent girls (grades 7-9) thought that obese people are just like normal weight people.

The social relationship category indicated that students' attitudes towards social relationships of overweight/obesity children were positive. The majority of the participants perceived that overweight/obese children are usually tidy, can expect to have normal lives, were not more emotional and do not tend to have more family problems than non-overweight/obese children. There was a slightly more positive attitude held by the 4-year program students. However, Strauss \& Pollack ${ }^{[30]}$ analyzed social networks of over-weight and normal-weight adolescents, and found that overweight adolescents appeared more socially marginalized and were more likely to be peripheral to social networks than were normal-weight adolescents.

Many studies indicated that health professionals believed that poor eating habits were one of the factors for children being overweight/obese. ${ }^{[1,31]}$ The participants in this study did not have these beliefs. All scores were mostly neutral on the beliefs scale. This indicates that nursing students need a greater understanding regarding healthy diets and how to support good eating behaviours for children. A study by Neumark-Sztainer, Story, and Harris ${ }^{[32]}$ showed that the 
majority of responses from high schools including teachers, school nurses and social workers indicated that obesity is caused by individual behaviour, such as poor eating behaviour. The literature revealed that eating pattern and type of food intake such as sugar-sweetened beverages ${ }^{[33]}$ is closely associated with body weight gain in children.

\subsection{Limitations}

This study was limited to nursing students in one university in Taiwan. The results of this study may not reflect the perceptions of student nurses in other regions in Taiwan, therefore there is limited generalizability. There is no way to identify why students had positive perceptions of children who are overweight/obese.

\subsection{Impact statement}

Overweight/obesity is an important public health issue. This is the first study about student nurses' attitudes of childhood overweight/obesity in Taiwan. The result of this research indicated that undergraduate students have positive attitudes about children who are overweight/obese. The data from this study can be used for developing curricula to promote nursing education on this issue.

\section{REFERENCES}

[1] Liou TH, Huang YC, Chou P. Prevalence and secular trends in overweight and obese Taiwanese children and adolescents in 1991-2003. Annals of Human Biology. 2009; 36(2): 176-185. PMid: 19255914. https ://doi.org/10.1080/03014460802691174

[2] Health Promotion Administration, Ministry of Health and Welfare, Taiwan. 2016 Annual report of health promotion administration. 2017 Available from: https://www.hpa.gov.tw/EngPages/Detail . aspx?nodeid=1072\&pid=7183

[3] American Diabetes Association. Type 2 diabetes in children and adolescents. Pediatrics. 2000; 105(3): 671-680. https://doi.org/10 .1542 /peds.105.3.671

[4] Alonso-Álvarez ML, Cordero-Guevara JA, Terán-Santos J, et al. Obstructive sleep apnea in obese community-dwelling children: The NANOS study. Sleep. 2014; 37(5): 943-949. PMid: 24790273. https://doi.org/10.5665/sleep. 3666

[5] Wardle J, Cooke L. The impact of obesity on psychological well-being. Best Practice \& Research Clinical Endocrinology \& Metabolism. 2005; 19(3): 421-440. PMid: 16150384. https : //doi.org/10.1016/j.beem.2005.04.006

[6] Lee YC, Chuang HT. The effects of parental factors on the weight of school-aged children. Journal of Tzu Chi College of Technology. 2015; 24: 19-31.

[7] Thibault H, Carriere C, Langevin C, et al. Prevalence and factors associated with overweight and obesity in French primary-school children Public Health Nutrition. 2013; 16(2): 193-201. PMid: 22953729. https ://doi.org/10.1017/S136898001200359X

\section{Conclusions}

Health professional's attitude and belief can effect quality of care for patients. In our study, students reported positive attitudes and beliefs about children who are overweight/obese. The result can be influenced by the culture and the role of the nursing student. Moreover, the negative attitudes can be underlying and automatically activated. ${ }^{[34]}$ The participants in this study were undertaking nursing education, therefore, it is possible that their professional education and role may have affected their attitudes towards overweight/obese children. Researchers found that education can decrease nurses' negative attitudes toward overweight/obese patients. ${ }^{[10,14]}$ Effective education about children who are overweigh/obesity is important at undergraduate level as it can have a positive impact on their practice with these children. The data from this study can provide information for the development of curricula for nursing students. Further research with nursing students and children who are overweigh/obesity may provide a broader perspective and help to improve patient care outcomes.

\section{CONFlicts OF InTEREST Disclosure}

The authors declare they have no conflicts of interest.
[8] Foster GD, Wadden TA, Makris AP, et al. Primary care physicians' attitudes about obesity and its treatment. Obesity. 2003; 11(10): 11681177. PMid: 14569041. https://doi.org/10.1038/oby. 2003 .161

[9] Ward-Smith P, Peterson JA. Development of an instrument to assess nurse practitioner attitudes and beliefs about obesity. Journal of the American Association of Nurse Practitioners. 2016; 28(3): 125-129. PMid: 26178582. https : //doi .org/10.1002/2327-6 924.12281

[10] Gujral H, Tea C, Sheridan M. Evaluation of nurse's attitudes toward adult patients of size. Surgery for Obesity and Related Diseases. 2011; 7(4): 536-540. PMid: 21676657. https ://doi.org/10.1 016/j.soard.2011.03.008

[11] Snethen JA, Treisman RA, Buseh AG, et al. Exploring future nurses' attitudes and beliefs related to childhood overweight. Journal of Nursing Education. 2014; 53: S101-S105. PMid: 25102129. https://doi.org/10.3928/01484834-20140806-03

[12] Tsai TI, Luck L, Jefferies D, et al. Exploring nurses' knowledge and attitudes about children who are overweight/obese: A review of the literature. Clinical Nursing Studies. 2017; 5(1): 50-56. https : //doi.org/10.5430/cns.v5n1p50

[13] Shea JM, Gagnon M. Working With Patients Living With Obesity in the Intensive Care Unit: A Study of Nurses' Experiences. Advances in Nursing Science. 2015; 38(3): E17-E37. PMid: 26061972. https://doi.org/10.1097/ANS.0000000000000074

[14] Falker AJ, Sledge JA. Utilizing a bariatric sensitivity educational module to decrease bariatric stigmatization by healthcare profession- 
als. Bariatric Nursing and Surgical Patient Care. 2011; 6(2): 73-78. https ://doi.org/10.1089/bar.2011.9974

[15] Marcum L. Effectiveness of obesity sensitivity education on changing attitudes and beliefs of nurses and nursing students. (Unpublished doctoral dissertation). College of Saint Mary, Omaha, NE. 2009.

[16] Zuzelo PR, Seminara P. Influence of registered nurses' attitudes toward bariatric patients on educational programming effectiveness. The Journal of Continuing Education in Nursing. 2006; 37(2): 65-73. https://doi.org/10.3928/00220124-20060201-02

[17] Godin G, Kok G. The theory of planned behavior: A review of its applications to health-related behaviors. American Journal of Health Promotion. 1996; 11(2): 87-98. PMid: 10163601. https: //doi.org/10.4278/0890-1171-11.2.87

[18] Ajzen I. The theory of planned behavior. Organizational Behavior and Human Decision Processes. 1991; 50(2): 179-211. https: //doi.org/10.1016/0749-5978(91)90020-T

[19] Soanes C, Stevenson A. Oxford dictionary of English. 3rd ed. Oxford, New York: Oxford University Press; 2010.

[20] Schmidt NA, Brown JM. Evidence-based practice for nurses: Appraisal and application of research. 2nd ed. Ontario: Jones \& Bartlett Learning; 2012.

[21] Allison DB. Handbook of assessment methods for eating behaviors and weight-related problems: Measures, theory, and research. Thousand Oaks, CA: Sage; 1995.

[22] Tsai TI, Luck L, Jefferies D, et al. A tool to measure the attitudes and beliefs of nursing students towards childhood overweight/obesity. Collegian. 2018a; 25: 341-345. https://doi.org/10.1016/j. colegn. 2017.10.005

[23] Brislin RW. Back-translation for cross-cultural research. Journal of Cross-Cultural Psychology. 1970; 1(3): 185-216. https://doi .or g/10.1177/135910457000100301

[24] Beaton DE, Bombardier C, Guillemin F, et al. Guidelines for the process of cross-cultural adaptation of self-report measures. Spine. 2000; 25(24): 3186-3191. PMid: 11124735. https ://doi .org/10 .1097/00007632-200012150-00014

[25] Tsai TI, Luck L, Jefferies D, et al. Challenges in adapting a survey: Ensuring cross-cultural equivalence. Nurse Researcher. 2018b; 26(1):
28-32. PMid: 29856168. https://doi.org/10.7748/nr. 2018. e1581

[26] IBM Corp. IBM SPSS statistics for windows (version 22). Armonk, NY: IBM Corp; 2016.

[27] Wong OL. Meaning of food in childhood obesity: An exploratory study in a Chinese family context. Social Work in Health Care. 2010; 49(4): 362-377. PMid: 20379905. https://doi.org/10.1080/ 00981380903212149

[28] Marsh HW, Hau KT, Sung RY, et al. Childhood obesity, gender, actual-ideal body image discrepancies, and physical self-concept in Hong Kong children: Cultural differences in the value of moderation. Developmental Psychology. 2007; 43(3): 647-662. PMid: 17484577. https://doi.org/10.1037/0012-1649.43.3.647

[29] Chen LJ, Fox KR, Haase AM. Body image and physical activity among overweight and obese girls in Taiwan. Women's Studies International Forum. 2010; 33: 234-243. https ://doi.org/10.1016/ j.wsif. 2010.01.003

[30] Strauss RS, Pollack HA. Social marginalization of overweight children. Archives of Pediatrics \& Adolescent Medicine. 2003; 157(8): 746-752. PMid: 12912779. https://doi.org/10.1001/archpe di.157.8.746

[31] Nauta C, Byrne C, Wesley Y. School nurses and childhood obesity: An investigation of knowledge and practice among school nurses as they relate to childhood obesity. Issues in Comprehensive Pediatric Nursing. 2009; 32(1): 16-30. PMid: 19263291. https://doi.org/10.1080/01460860802610186

[32] Neumark-Sztainer D, Story M, Harris T. Beliefs and attitudes about obesity among teachers and school health care providers working with adolescents. Journal of Nutrition Education. 1999; 31(1): 3-9. https ://doi .org/10.1016/S0022-3182(99)70378-X

[33] Malik VS, Pan A, Willett WC, et al. Sugar-sweetened beverages and weight gain in children and adults: A systematic review and metaanalysis. The American Journal of Clinical Nutrition. 2013; 98(4): 1084-1102. PMid: 23966427. https://doi.org/10.3945/ajcn .113 .058362

[34] Bessenoff G, Sherman J. Automatic and Controlled Components of Prejudice Toward Fat People: Evaluation Versus Stereotype Activation. Social Cognition. 2000; 18(4): 329-353. https ://doi .org/ 10.1521 /soco. 2000.18 .4 .329 